\title{
Autonomía privada existencial y capacidad de hecho para personas con discapacidad mental o intelectual
}

\author{
A autonomia privada existencial e a capacidade de fato das pessoas com deficiência \\ mental ou intelectual
}
Existential private automomy and fact capacity for people with mental or intellectual disabilities

\author{
lara Antunes de Souza* \\ Rafaela Fernandes Leite** \\ Priscilla Jordanne Silva Oliveira ${ }^{*+*}$
}

\section{Resumen}

El objetivo es, utilizando el método formal de interpretación, considerar la verdadera aspiración del derecho a ser una práctica normativa inmanentemente inteligible, cuestionar si la revisión de la Teoría de las Capacidades Civiles expresa una idea justificante única y coherente cuando se ve desde capacidad de hecho y la autonomía privada existencial de las personas con discapacidad mental o intelectual, basada en la a la Convención Internacional sobre los Derechos de las Personas con Discapacidad y el Estatuto para las Personas con Discapacidad. Se investigan tres hipótesis: a) si existe una base independiente para la autonomía privada que rompe con la discapacidad real, sin promover la ruptura de la unidad justificadora de los institutos; b) si existe un concepto de autonomía que no depende de ese concepto dada la autonomía privada, lo que indica el uso de un concepto externo al derecho; o c) si hay una distorsión de la realidad objetiva de las personas con discapacidad por la imposición de un criterio formal e indeseable de igualdad que rompe, incoherentemente, con la continuidad entre la capacidad de hecho y la autonomía privada. Al final, se confirma la última hipótesis, ya que las personas con discapacidades mentales o intelectuales fueron tratadas como igualmente autónomas para la práctica de actos jurídicos y negocios jurídicos existenciales, a pesar del eventual reconocimiento de su impedimento para expresar una voluntad discernida y consciente.

Palabras clave: Autonomía privada. Idoneidad. Personas con discapacidad. Teoría de las capacidades civiles. Derechosexistenciales.

\section{Resumo}

Objetiva-se, utilizando-se o método formalista de interpretação, considerando a verdadeira aspiração do direito de ser uma prática normativa imanentemente inteligível, questionar se a revisão da Teoria das Capacidades Civis expressa uma ideia justificatória única e coerente quando perspectivada a capacidade de fato e a autonomia privada existencial das pessoas com deficiência mental ou intelectual, a partir da Convenção Internacional sobre os Direitos das Pessoas com Deficiência e do Estatuto da Pessoa com Deficiência. São investigadas três hipóteses: a) se há uma fundamentação independente para a autonomia privada que rompe com a incapacidade de fato, sem promover a quebra da unidade justificatória dos institutos; b) se há uma concepção de autonomia que independe daquela concepção dada a autonomia privada, o que indica o recurso a uma concepção externa ao direito; ou c) se há uma distorção da realidade fática das pessoas com deficiência pela imposição de um critério formal e indesejável de igualdade que rompe, incoerentemente, com a continuidade entre a capacidade de fato e a autonomia privada. Ao final, é confirmada a última hipótese, eis que as pessoas com deficiência mental ou intelectual foram tratadas como igualmente autônomas para prática dos atos e negócios jurídicos existenciais, não obstante o reconhecimento eventual do seu impedimento para exprimir vontade discernida e consciente.

Palavras-chave: Autonomia Privada. Capacidade de Fato. Pessoas com Deficiência. Teoria das Capacidades Civis. Direitos Existenciais.

Doutora e Mestre em Direito Privado pela Pontifícia Universidade Católica de Minas Gerais, PUC-MG, Brasil. Professora da graduação e do mestrado acadêmico Novos Direitos, Novos Sujeitos da Universidade Federal de Ouro Preto, UFOP. Pesquisadora do Centro de Estudos em Biodireito, CEBID. E-mail: iara@ufop.edu.br.

Doutoranda em Direito Civil pela Universidade Federal de Minas Gerais, UFMG, Brasil. Mestre em Direito pela Universidade Federal de Ouro Preto, UFOP, Brasil. Pesquisadora do Centro de Estudos em Biodireito, CEBID/UFOP. E-mail: leitefrafaela@gmail.com.

(9) Mestre em Direito pela Universidade Federal de Ouro Preto, UFOP, Brasil. Especialização em Direito Civil, Pontifícia Universidade Católica de Minas Gerais, PUC Minas, Brasil. Professora no Centro Universitário Estácio de Belo Horizonte, Brasil. Pesquisadora do Centro de Estudos em Biodireito, CEBID/UFOP. E-mail: priscillajsoliveira@gmail.com. 


\begin{abstract}
The purpose of this article is, using the formalistic method of interpretation, considering the true aspiration of the right to be an immanently intelligible normative practice, to question whether the review of Theory of Civil Capabilities expresses a unique justifying idea and coherent when looking at the fact capacity and existential private autonomy for people with mental or intellectual disabilities, from the International Convention on the Rights of Persons with Disabilities and the Status of Persons with Disabilities. Three hypotheses are investigated: a) if there is an independent basis for private autonomy that breaks with the disability in fact, without promoting the breaking of the justification unit of the institutes; b) if there is a conception of autonomy that doesn't depend on that conception given the private autonomy, which indicates the use of a conception external to the law; or c) if there is a distortion of the factual reality of people with disabilities by imposing a formal and undesirable equality criterion that breaks, incoherently, with the continuity between fact capacity and private autonomy. In the end, the last hypothesis is confirmed behold, people with mental or intellectual disabilities were treated as equally autonomous for the practice of existential legal acts and business, notwithstanding the eventual recognition of its impediment to express discerned and conscious will.
\end{abstract}

Keywords: Private Autonomy. Fact Capacity. Disabled People. Theory of Civil Capabilities. Existential Rights.

\title{
1. Introducción
}

La autonomía refleja conceptos diversos y significativamente controvertidos en las construcciones teóricas filosóficas, políticas y críticas ${ }^{1}$ que recurrieron a ella. Por lo tanto, el uso del sustantivo autonomía asociado con la partícula privada ${ }^{2}$ se utiliza en este artículo para determinar y restringir el derecho privado como su ámbito de análisis, en el que expresa el poder de disposición conferido por la norma jurídica a las personas capaces, de modo a crear normas que puedan gobernar la relación entre ellas, reservándoles espacios de libertad incompatibles con la interferencia del poder público en el ámbito patrimonial y existencial.

Sin embargo, el poder conferido a los individuos por la autonomía privada está condicionado a la calidad de la voluntad que entrará en el mundo jurídico y la aptitud de su titular para formular, hacer inferencias, revisar y concretar posiciones y actos jurídicos de manera consciente, siendo responsablesde ellos. Esta aptitud fue reconocida por la Teoría de las Capacidades Civiles en la atribución de la capacidad de hecho ${ }^{3}$ a aquellas personas que cumplían veintiún o dieciocho años, respectivamente, en el Código Civil de Brasil de $1916^{4}$ y $2002^{5}$.

El criterio de edad, que asumió la capacidad y aptitud de las personas para los actos de la vida civil, ha sido históricamente relativizado por la noción abstracta de anormalidad psíquica, de la cual las personas con discapacidades mentales e intelectuales se enumeraron entre las hipótesis de discapacidad de hecho absoluta y/o relativa. Sin embargo, la diversidad de discapacidades mentales e intelectuales a largo plazo se redujo en el uso de expresiones locos de todo tipo, enfermos y discapacitados mentales ${ }^{6}$, que se utilizaron para indicar las hipótesis de supresión de la capacidad de hecho de las personas con discapacidad para el ejercicio de actos civiles patrimoniales y existenciales, sin distinción.

Por ejemplo, se cita el contenido integral que se le atribuye en la filosofía de John Stuart Mill en On Liberty, publicado originalmente en 1859; El contenido político empleado por John Rawls en PoliticalLiberalism, publicado en 1993 y otro de la teoría crítica empleada por NatáliaLisbôa e lara Souza, en Autonomia privada e colonialidade de gênero, publicada en 2019.

2 La distinción entre autonomía de la voluntad y autonomía privada no es ignorada por los autores, aunque no se le atribuye ninguna controversia sustancial para el desarrollo de este artículo. Por lo tanto, al adoptar el uso de la partícula privada, se reconoce la relevancia de la autonomía de la voluntad en el tratamiento de la libertad comercial por parte del derecho privado en el contexto del movimiento de codificación que ocurrió entre los siglos XVIII y XIX. Incluso en Brasil, cuando se promulgó el Código Civil de 1916, en el que la distancia del Estado de las relaciones comerciales privadas y la voluntad de las partes era evidente, lo que no fue objeto de verificación posterior, excepto por el incumplimiento del formulario. Sin embargo, este entendimiento ya no refleja el estado actual de las cosas y los cambios ocasionales, sino expresivo en el derecho contractual en el Código Civil de 2002, como lo demuestra la introducción normativa de la cláusula rebus sic stantibus, además de las limitaciones contractuales características de las relaciones privadas de empleo y consumo, típico del siglo XX. Por lo tanto, como lo enfatizó OtávioLuizRodrigues Junior (2004, p. 121), la demanda heterogénea del Estado Social en el derecho privado promovió un cierto repudio del término voluntad y destacó la partícula privada. También hay una referencia a la autonomía de la voluntad como una expresión de la voluntad psicológica interna del agente que la expresa, como lo recuerdan Luigi Ferri (2001, p. 5) y Francisco dos Santos Amaral Neto (1989, p. 213). Sin embargo, no hay elementos empíricos para indicar que esta connotación ha sido estructuralmente adoptada por el derecho privado.

3 La capacidad, de hecho, no debe confundirse, por lo tanto, con la capacidad de derecho que se atribuye de manera lineal a todas las personas naturales desde su nacimiento con vida. La capacidad de la ley no depende del estado de conciencia, el grado de discernimiento y el desarrollo cognitivo individual de las personas físicas, como lo enfatiza Mariana Alves Lara (2019, p. 41) en un trabajo reciente.

4 En el Código Civil de 1916, el criterio de edad fue establecido por el artículo 9, que decía que: "A la edad de veintiún años, termina la edad de la minoría y el individuo está calificado para todos los actos de la vida civil".

5 En el Código Civil de 2002, el criterio de edad se establece en el artículo 5, que dice que: "La minoría cesa a la edad de dieciocho años, cuando la persona está calificada para practicar todos los actos de la vida civil".

6 Terminologías utilizadas en el desarrollo de la Teoría de las Capacidades y en los Códigos Civiles de Brasil de 1916 y 2002 para el encuadre de personas con discapacidad mental o intelectual. 
En este contexto, la aprobación de la Convención Internacional sobre los Derechos de las Personas con Discapacidad (CDPD), conocida como la Carta de Nueva York, por Brasil con el estado de enmienda constitucional ${ }^{7}$ y la promulgación del Estatuto para las Personas con Discapacidad (EPD) promovió un cambio en paradigma en la teoría de las capacidades civiles al eliminar la discapacidad o la enfermedad de la hipótesis de incapacidad y determinar la capacidad civil completa de las personas con discapacidad mental o intelectual, incluido para el ejercicio de derechos subjetivos existenciales ${ }^{8}$ en circunstancias con implicaciones inmediatas en el derecho de las obligaciones y para lo cual se requería la aptitud de su titular para discernir sobre sus efectos personales y patrimoniales.

La interpretación literal de dicha modificación es consistente con el entendimiento de que la autonomía privada en ámbito existencial fue atribuida a las personas con discapacidad mental o intelectual para que se casen, formen una pareja de hecho y ejerzan el derecho de tutela, custodia y adopción, a pesar del posible reconocimiento de su impedimento para expresar voluntad consciente, causa actual de discapacidad relativa común a las personas con y sin discapacidad con lastre en la noción de discernimiento como capacidad de razonamiento.

Por ejemplo, a alguien que se considere relativamente incapaz de firmar personalmente un contrato de compra y venta se le permite ser invertida, sin embargo, con el poder de casarse, creando una aparente discontinuidad justificante entre la capacidad de hecho y la autonomía privada existencial de las personas con discapacidad mental o intelectual. Además, está claro que la Teoría de las Capacidades Civiles no refleja una unidad de protección para aquellos que no tienen el discernimiento necesario para manifestar o declarar una voluntad consciente y que, sin embargo, se consideran aptos para practicar actos jurídicos que pueden poner en riesgo su patrimonio e integridad psicofísica.

En vista de esto, suponiendo que es verdadera la aspiración del derecho a ser una práctica normativa inmanentemente inteligible (WEINRIB, 2011, na p. 259), el método formal de interpretación ${ }^{9}$ a se utiliza para cuestionar si la revisión de la Teoría de las Capacidades Civiles expresó una idea de justificación única y coherente cuando se observa la capacidad de hechoy la autonomía privada existencial de las personas con discapacidad mental o intelectual, basada en la CDPD y el EPD.

En este sentido, se considerarán tres hipótesis como posibles resultados de la revisión de la Teoría de las Capacidades Civiles en la relación entre la autonomía privada existencial y la capacidad de hecho de las personas con discapacidad mental o intelectual: a) existe una base independiente para la autonomía privada que rompe con la incapacidad de hecho, sin romper la unidad de justificación de estos institutos; b) existe un concepto de autonomía que es independiente de ese concepto dada la autonomía privada, que indica el uso de un concepto externo al derecho privado; o c) hay una distorsión de la realidad objetiva de las personas con discapacidad por la imposición de un criterio formal e indeseable de igualdad que rompe, incoherentemente, con la continuidad entre la capacidad de hecho y la autonomía privada.

Para definir qué hipótesis es verdadera, en la primera sección se desarrollará el concepto de autonomía privada y su relación con la capacidad real, en la segunda sección, para analizar si la revisión de la Teoría de las Capacidades Civiles afecta a esa relación y si renuncia a crear un régimen jurídico que aparentemente es diverso y autónomo para las cuestiones existenciales.

Esta investigación está vinculada a los aspectos metodológico jurídico-dogmático y jurídico-teórico (GUSTIN; DIAS, 2002), desarrollado con miras a comprender la estructura interna que unifica y justifica la teoría de las capacidades. Esta investigación se sitúa entre diferentes sectores del conocimiento, configurándose como interdisciplinar. Para el procesamiento de los datos primarios y secundarios analizados se utilizó el razonamiento deductivo.

$7 \quad$ La CDPD fue aprobada por el Congreso Nacional de Brasil mediante el Decreto Legislativo no. 186, del 9 de julio de 2008, el primer tratado de Derechos Humanos recibido con fuerza de enmienda constitucional, debido a su aprobación de acuerdo con el procedimiento del artículo 5 , §3 de la Constitución de la República. La CDPD fue promulgada y publicada a través del Decreto no. 6,949 , con fecha 25 de agosto de 2009 , fecha de vigencia.

$8 \quad$ Interpretación literal tomada del Artículo 6 del EPD, como se mostrará.

9 El formalismo se está utilizando en este texto como una estrategia interpretativa, un sentido utilizado por Cass R. Sustein (2011, p. 204-205). Por lo tanto, se compartirán los compromisos que tal estrategia requiere, a saber: promover el cumplimiento de las formalidades jurídicas aplicables: asegurar como resultado un derecho vinculado a las reglas analizadas; limitar la discreción de los jueces al decidir los casos específicos relacionados con el tema que se conjetura. Cabe señalar, sin embargo, que no existe una concepción única sobre el formalismo, ni un consenso sobre esa teoría. Para una comprensión del formalismo jurídico y su relevancia en diferentes áreas del conocimiento, se recomienda el libro La justificación del formalismo jurídico, organizado por José Rodrigo Rodrigues y publicado en 2011. 


\section{Autonomía privada y la teoría de las capacidades civiles}

La autonomía privada designa la porción de libertad individual que puede ser objeto de relaciones jurídicas establecidas entre individuos. Es, por lo tanto, una capacidad jurídica para el autogobierno que está sujeta a los límites de la ley que la constituye. A diferencia de lo que sucede con la libertad de las personas de autodeterminarse dentro de los límites de lo estrictamente personal, como en la definición libre de sus gustos, preferencias y concepciones del bien.

Definitivamente, la autonomía privada y la libertad de acción humana no son lo mismo. La razón por la cual esta afirmación es verdadera se puede expresar en la distinción formulada por Ana Prata (2016, p. 14-15) al sugerir que: "Por un lado, la autonomía privada no designa toda la libertad, no toda la libertad privada, ni siquiera toda la libertad jurídica privada, sino solo un aspecto de esta última: la libertad negocial".

Dicho esto, la autonomía privada debe considerarse un fenómeno interno del derecho y no un fenómeno social o una libertad natural, como observó Luigi Ferri $(2001$, p. 7) al recopilar y analizar la literatura sobre el concepto de autonomía privada. Es, en las palabras del autor, una "[...] manifestación de poder y precisamente el poder de crear, dentro de los límites establecidos por la ley, normas jurídicas". En el mismo sentido, citan-se Bruno Torquato de Oliveira Naves (2014, p. 96-97), Rose Melo Vencelau Meireles (2009, p. 74), Francisco Hupsel (2016, p. 76-77), Ana Prata (2016, p. 13) y Francisco dos Santos Amaral Neto (1989, p. 213).

La correspondencia entre lo que las personas son y quieren y lo que están jurídicamente autorizadas para ser y hacer, expresa el contenido del poder dispositivo reservado para ellos por el fenómeno de la autonomía privada en el ejercicio de su libertad negocial. La autonomía privada se afirma, por lo tanto, como un poder de disposición que tiene su correlación inmediata en el negocio jurídico (FERRI, 2001, p. 88; 246-253), aplicando prominentemente en el derecho de las obligaciones, independientemente de la especie (dar, hacer o no hacer) 0 la naturaleza del objeto de provisión (patrimonial o existencial).

El negocio jurídico como [...] "instrumento para lograr la autonomía privada, es una declaración de la voluntad de crear normas jurídicas", (AMARAL NETO, 1989, p. 13), para lo cual se requiere la capacidad de hecho ${ }^{10}$. La autonomía privada es parte de un esquema más amplio de justificación de las relaciones jurídicas y su atribución está condicionada a la capacidad de hecho de la persona física, ya que es el poder que proviene de la Ley y no puramente de la voluntad humana ${ }^{11}$.

El desarrollo de un esquema legal para evaluar la idoneidad de las personas físicas para la vida civil y que regularacoherentemente los derechos de propiedad y la libertad contractual ${ }^{12}$, fue impulsado por Augusto Teixeira de Freitas ${ }^{13}$, quien trabajó en la consolidación delderecho vigente en país, publicado en 1857 bajo el nombre de Consolidación de Leyes Civiles y, más tarde, con la preparación del primer borrador del Código Civil, publicado entre 1860 y 1865 (ROBERTO, 2011, p. 59-63), oportunidades en las que la palabra capacidad ya se consideraba como una categoría jurídica de análisis de la aptitud de las personas físicas para los actos de la vida civil y que estaba influenciada por la edad, la locura y la prodigalidad (FREITAS, 2003, p. 256; 269), aunque sin la actual precisión jurídica que se utiliza, como detalla Felipe Quintella Machado de Carvalho (2013, p. 107).

La mejora de una Teoría de las Capacidades Civiles surge con la publicación del Borrador del de Código Civil, el primer anteproyecto del Código Civil brasileño, y establece dos tipos distintos de capacidad: la capacidad de derecho y la capacidad de hecho. La capacidad de derecho expresa la capacidad común de las personas físicas para adquirir y ser titulares de los derechos desde su nacimiento con vida. La capacidad real, a su vez, es atribuida por el sistema jurídico desde el cumplimiento de cierta edad a aquellos que presumiblemente pueden ejercerla.

A pesar de la generalidad subyacente a la Teoría, se consideró algunas subjetividades para tratar de la incapacidad de aquellos que alcanzaron la mayoría de edad civil. Por lo tanto, Augusto Teixeira de Freitas propuso, en el artículo 22 del anteproyecto, que aquellos que no podían trabajar física o moralmente, o que debido a su

10 En el Código Civil brasileño, la capacidad se considera un requisito para la validez del negocio jurídico, y la voluntad consciente es un requisito para la existencia de actos jurídicosstricto sensu y negocios jurídicos.

1 Como también enfatizó Bruno Torquato de Oliveira Naves (2014, p. 101).

12 Objetivos relevantes para la afirmación del régimen de producción capitalista, cuya influencia marcó el movimiento de codificación en Occidente y, específicamente, en Brasil. (GOMES, 2006, p. 14); (ROBERTO, 2011).

13 La relación entre Augusto Teixeira de Freitas y la Teoría de las capacidades fue destacada por Felipe Quintella Machado de Carvalho (2013, p. 95-110). 
dependencia de una representación necesaria, no podían realizar personalmente los actos de la vida civil, deberían considerarse incapaces de hecho.

Al equiparar a las personas que son incapaces física o moralmente de trabajar, Augusto Teixeira de Freitas incluyó en esta categoría a los sordos y aquellos considerados alienados ${ }^{14}$, personas con discapacidades mentales o intelectuales que fueron reducidas en esta categoría. La opción del jurista habría sido respaldada por el enfoque de la discapacidad según el modelo médico ${ }^{15}$, ya que la noción de capacidad se derivaba de la referencia binaria de normalidad y, por lo tanto, de la capacidad-discapacidad.

Las personas con discapacidad mental o intelectual, nuevamente referidas por la expresión "locos de todo tipo", también fueron incluidas entre las absolutamente incapaces por ClóvisBeviláqua al redactar el proyecto legislativo que culminó en el Código Civil de 1916 y en la redacción utilizada en su artículo 5.

La opción de ClóvisBeviláqua al ratificar el criterio de discapacidad adoptado por Augusto Teixeira de Freitas, por el cual se prefería decir quiénes eran los incapacitados para decir en qué consistía la discapacidad, fue criticada, en ese momento, por el profesor de medicina legal de la Facultad de Medicinade Bahía, Nina Rodrigues (BRASIL, 1917, p. 210-216, v. II), quien en una opinión solicitada por la Cámara de Diputados, juzgó que sería imposible incluir en la designación de locos de todo tipo solo por una convención de puro arbitraje, todos los casos transitorios o permanentes de incapacidad civil debido a anormalidades o disturbios psíquicos.

El Código Civil de 2002 mitigó los efectos de la discapacidad para la persona con discapacidad mental o intelectual al relacionarla entre las hipótesis de discapacidad absoluta y relativa, indicadas respectivamente en sus artículos 3 y 4 , sin embargo, condicionando los efectos de la discapacidad al grado de afectación de su discernimiento, manteniendo el referencial del modelo médico.

De este modo, se mantiene la indicación de quiénes son los incapacitados y se perpetúa la omisión normativa en cuanto a la situación de hecho que genera la inaptitud para los actos de la vida civil, y la crítica opuesta por Renata Barbosa de Almeida (2011, p. 74-75) es pertinente en relación con estas dos categorías, consideradas tradicionalmente impensables, ya que son incompatibles con las características individuales de los sujetos ahora sofocados por la norma jurídica.

El régimen jurídico atribuido a las discapacidades en los códigos de 1916 y 2002 fue similar. Por lo tanto, presentada una demanda contra una persona con discapacidad mental o intelectual mayor de veintiún o dieciocho años de edad, y si se reconocía su discapacidad absoluta o relativa, estaba sujeta a un tutor, cuyo ejercicio se realizó a través de figuras de representación y asistencia, respectivamente.

A través de la representación, se habría transferido la gestión de la vida civil de los incapacitados a su tutor, quien podría ejercer su cargo de manera discrecional y arbitraria, ya que fue liberado de considerar cualquier elemento restante de la voluntad, las preferencias o los posibles intereses del incapaz representado. La asistencia, a su vez, especificaba una forma especial de autorización que condicionaba la validez de los negocios jurídicos concluidos por los relativamente incapaces a la aquiescencia de su tutor.

El reconocimiento de la incapacidad real de las personas con discapacidades mentales o intelectuales no permitia gradaciones de intensidad, ni deja intacta ninguna situación o posible relación jurídica, ya sea de naturaleza patrimonial o existencial. Por lo tanto, la persona discapacitada se suponía capaz o se reconocía como incapaz. Si era absolutamente incapaz, no había razón para considerar posibles contornos de su autonomía privada, ya que si incapaz, no tenía ese poder jurídico. Y, si era relativamente incapaz, el ejercicio de su autonomía dependía del consentimiento de su tutor. Por lo tanto, la aparente ausencia de trabajos académicos que hayan problematizado los contornos de la autonomía privada de la persona con discapacidad hasta la aprobación de la CDPD en 2009 y la promulgación del EPD en 2015 no es sorprendente.

En ambos casos, la relevancia jurídica del tutor en el proceso negocial impuso a la persona representada o asistió el papel de un mero adyuvante, con la eliminación de la autonomía en el primer caso y el agotamiento de su fuerza en el segundo.

14 La falta de discernimiento o el discernimiento reducido o incompleto fue la razón de la incapacidad de los menores sin importancia y de aquellos considerados alienados. La palabra, sin embargo, fue modificada entre la Consolidación de Leyes Civiles y el Esquema, ya que en ese primer Freitas (2003, p. 269) usó la expresión "locos de todo tipo", justificando, por eso, ignorando la variada terminología. solía tratarlos y optaba por la misma designación utilizada por el Código Penal de 1830.

15 Expresión utilizada para designar el período en que la discapacidad se convirtió en objeto de aprensión y conocimiento científico. El enfoque de la discapacidad por el modelo médico prevaleció entre los años 60 y 70, del siglo XIX. (BISOL, PEGORINI, VALENTINI, 2017, p. 90). Según ese modelo, el conocimiento médico se produce con autoridad especial para ordenar las prácticas relacionadas con discapacidades (FRANÇA, 2014, p. 110), que se cree que también influyó en el ordenamiento jurídico. 
Por otro lado, la continuidad entre la capacidad de hecho y la autonomía privada era evidente. En otras palabras, la persona considerada apta y capaz para la práctica de los actos de la vida civil se invertía en el poder conferido por la autonomía privada para autodeterminarse en las relaciones jurídicas establecidas, la calidad de derecho subjetivo involucrado, patrimonial o existencial, siendo solo un accesorio en la composición de su posición. En otras palabras, a los totalmente capaces se les dio autonomía privada para dar forma a su vida civil en un ámbito patrimonial y existencial, sin distinción.

Por lo tanto, tres conclusiones parciales parecen razonables: 1) aunque la autonomía privada se desarrolló conceptualmente sin recurrir a la Teoría de las Capacidades Civiles, su atribución depende de la capacidad real de las personas físicas; 2 ) no hay razones para considerar que otras concepciones de autonomía podrían afectar la relación de continuidad establecida entre la Teoría de las Capacidades Civiles y su concepción jurídica, mientras se realiza una interpretación formalista; 3 ) la premisa de igualdad de libertad que subyace en el derecho civil se justifica por la desigualdad fáctica de quienes no tienen aptitud para el ejercicio de la vida civil, independientemente de la idoneidad de sus criterios.

Si estas conclusiones pueden reafirmarse frente a la revisión de la Teoría de las Capacidades Civiles o si hay razones por las que pueden abandonarse y/o reemplazarse sin romper la unidad de la Teoría o comprometer su justificación, es una pregunta que se proyecta para la siguiente sección.

\section{La revisión de la teoría de las capacidades civiles}

La revisión de la Teoría de las Capacidades Civiles se refiere al conjunto de cambios y derogaciones impuestas por el EPD, bajo la influencia de la CDPD, en las hipótesis de incapacidad absoluta y relativa del Código Civil de Brasil de 2002, así como los cambios derivados de aquellos en la regulación delatutela y que, en particular, fueron causadas por la supresión de la discapacidad mental o intelectual como causa del reconocimiento de la discapacidad en cualquier grado. Por otro lado, el criterio de edad de dieciocho años se mantuvo como momento para atribuir la capacidad de hecho a las personas físicas.

Los cambios, que son más relevantes para este artículo y se ilustran a continuación, se implementaron en los artículos 3 y 4 de la redacción original del Código Civil, de donde se extrae que las hipótesis de incapacidad absoluta y relativa basadas en expresiones genéricas de discapacidad mental o intelectual se eliminaron de los artículos 3 y 4 , en la redacción dada por el EPD. La única situación de discapacidad absoluta en Brasil es la que se basa en el criterio de edad, común a las personas con y sin discapacidad.

Por lo tanto, reflejando las críticas previamente opuestas a las hipótesis de incapacidad, hay en el ítem III del artículo 4 tiene, entre las hipótesis de incapacidad relativa, una descripción objetiva de la incapacidad que se definió como el impedimento temporal o permanente, para expresar la voluntad. La hipótesis mencionada incluye la incapacidad absoluta del ítem III, del artículo 3, que fue revocado por el EPD, una oportunidad en la que también comenzó a considerar impedimentos permanentes.

Por lo tanto, el impedimento para expresar la voluntad puede afectar a personas con y sin discapacidad, sin distinción. La asociación entre voluntad y capacidad, ya expresada en la redacción original del Código Civil de 2002, estuvo presente en las discusiones emprendidas en el momento del proyecto Beviláqua para el Código Civil de 1916, guiando su justificación para excluir a las personas ciegas de las hipótesis de incapacidad ${ }^{16}$ y para condicionar el reconocimiento de la discapacidad de la persona sordomuda solo cuando no pueden expresar su voluntad.

El impedimento para expresar voluntad, transitorio o aparente, debe considerar cualquier obstáculo de naturaleza física, mental, intelectual o sensorial. Por esta razón, los impedimentos que enfrenta alguien para expresar su voluntad, haciéndolo evidente, son igualmente importantes, así como los impedimentos de naturaleza mental o intelectual que comprometen la formación de esa voluntad de una manera discernible.

Para justificar la falta de fidelización de una interpretación literal para esta hipótesis, se menciona, por analogía, que la calidad de la voluntad que guía la atribución de la culpabilidad en el Derecho Penal también es indispensable para su mera externalización que, en este caso, se produce a través de la acción. Por lo tanto,

16 Oportunidad en la que argumentó que: "La ceguera no crea obstáculos para la manifestación de la voluntad, no implica debilidad en las energías psíquicas, aunque la ausencia de un sentido de la visión debe determinar una restricción notable en el campo de las ideas. Por lo tanto, no hay razón para restringir la capacidad de los ciegos “. (BEVILÁQUA, 1906, p. 60) 
como se observó en otro trabajo (OLIVEIRA, 2020, 108-109), la culpabilidad de los agentes por la práctica de comportamientos tipificados en la modalidad intencional requiere que la voluntad del agente sea discernida ( $\mathrm{NUCCl}$, 2017, p. 181-190).

Por lo tanto, parece improbable que la voluntad satisfaga la capacidad de hecho, por la cual la persona está apta para practicar un acto-hecho jurídico; acto jurídico estricto sensu; negocios jurídicos (capacidad negocial) y actos ilegales en general (MIRANDA, 2000, p. 211), sea una voluntad sin intencionalidad (si esa situación es posible). Por lo tanto, por exclusión, se dice que es incapaz relativamente quien no tiene la aptitud necesaria para comprender los efectos de sus actos y determinarse a sí mismo de acuerdo con este entendimiento, una condición que ha sido expresada por la palabra discernimiento.

En este sentido, lara Antunes de Souza (2016, p. 364-365) ya sostenía que la relación entre personalidad, capacidad y discapacidad, indicaba el discernimiento con el criterio de verificación de la capacidad legal, aunque este criterio ya no se expresaba en los artículos que se ocupó de la incapacidad civil. Por lo tanto, es la presencia del discernimiento lo que asegura el ejercicio de la autonomía privada en el ámbito patrimonial y existencial, fomentando y garantizando el libre desarrollo de la personalidad de las personas físicas.

La relevancia del discernimiento después de la revisión de la Teoría de las capacidades civiles fue destacada por otros civilistas, entre ellos Raphael Furtado Carminate (2019, p. 24), Taisa Maria Macena de Lima y Jéssica Rodrigues Godinho (2019) y Mariana Lara (2019, p. 171).

Por lo tanto, se concluye que la capacidad es la regla para las personas mayores de dieciocho años, con o sin discapacidad, su supresión está relacionada con la falta de discernimiento de la persona cuya capacidad se está investigando. En el caso de una persona con discapacidad mental o intelectual, la configuración de la discapacidad depende de una evaluación biopsicosocial, realizada por un equipo multidisciplinario e interdisciplinario, en la forma del artículo 2, párrafo 1 del EPD. Por lo tanto, es evidente que la incapacidad no está vinculada a la discapacidad en sí, sino a la falta de discernimiento (SOUZA, 2016, p. 399).

En vista de esto, una vez que la evaluación biopsicosocial se haya llevado a cabo y las conclusiones del experto resultantes se registren en un informe, le corresponderá al juez evaluar la necesidad de un tutor para la persona con discapacidad con algún impedimento para expresar una voluntad, que en lo sucesivo se entiende como falta de discernimiento.

La posible definición de custodia de una persona con discapacidad es una medida extraordinaria y, según los términos de los artículos 84 y 85 del EPD, debe ser proporcional a las necesidades y circunstancias de cada caso, otorgando al tutor poderes de asistencia que se extiendan solo a actos jurídicos subjetivos patrimonial y negocial practicada por el custodia.

Es decir, a pesar de que se reconoce la falta de discernimiento de la persona con discapacidad mental o intelectual y se declara su incapacidad relativa, el artículo 6 del EPD determina que la discapacidad no afecta la capacidad civil plena de la persona (es decir, la acumulación de su capacidad de derecho y de hecho), para casarse y formar una pareja de hecho; ejercer los derechos sexuales y reproductivos; ejercer el derecho de decidir sobre el número de hijos y tener acceso a información adecuada sobre reproducción y planificación familiar; conservar su fertilidad, quedando prohibida la esterilización obligatoria; ejercer el derecho a la familia y la vida familiar y comunitaria; ejercer el derecho de custodia, tutela, tenencia y adopción, como adoptante o adoptado, en igualdad de condiciones con los demás.

Por lo tanto, las situaciones y relaciones jurídicas existenciales quedan excluidas del alcance de la actividad del tutor, es decir, aquellas cuyo contenido refleja inmediatamente los derechos subjetivos de la personalidad, que comprenden elementos constitutivos del sujeto, entre los cuales se encuentran su cuerpo, sus convicciones, afectos, sus intimidades, honor, sus rasgos de personalidad y su percepción estética (DABIN, 2006, p. 125-224).

En este punto, existe una influencia inmediata de la CDPD, que en sus artículos 12 y 23 estableció la igualdad de trato de las personas con discapacidad ante la ley, incluidos los aspectos relacionados con el matrimonio, la familia, la paternidad y las relaciones. La igualdad de trato en este caso crea ficción jurídica, ya que supone que el derecho es suficiente para asignar una habilidad específica cuando, eventualmente, puede no existir.

Dado esto, no hay razones aparentes para concluir que no hay necesidad de mantener un tratamiento desigual y protector para las personas con discapacidades mentales o intelectuales, quien se les impide expresar una voluntad consciente y perspicaz que justificó, sin perjuicio de las críticas que se le opusieron, criterios para adquisición de la capacidad de hecho y la atribución de autonomía privada en consideración a la capacidad de 
la persona natural para manifestar y expresar voluntad consciente. Por lo tanto, por ahora, no hay razones para refutar las conclusiones parciales presentadas al final de la sección anterior.

Si la autonomía privada siempre se ha integrado coherentemente con la capacidad real, la pregunta restante es si la redacción realizada en el artículo 6 del EPD puede haber creado una hipótesis para la atribución de la autonomía privada existencial que no depende de la capacidad de hecho. Es decir, el poder de la persona discapacitada para practicar actos jurídicos de esa naturaleza, sin embargo, se reconozca como relativamente incapaz. Una respuesta afirmativa a esta hipótesis depende de la existencia de una fuente autónoma de desarrollo de la autonomía privada a nivel existencial, que no se verificó, como se demostrará.

\subsection{La atribución de la autonomía existencial a las personas con discapacidad mental o intelectual}

Cuando las perspectivas de las situaciones existenciales y patrimoniales se consideran áreas cualitativamente diferentes para el ejercicio de la autonomía privada, es necesario aclarar que no es la autonomía privada la que cambia, sino la situación jurídica a la que se dirige. En este sentido, existe la distinción hecha por Pietro Perlingieri (2007, p. 105-107) y más tarde por Rose Melo Vencelau Meireles (2009, p. 22), del análisis de los perfiles de la situación jurídica y, especialmente, el de interés (demuestra para qué sirve) y el funcional (demuestra para qué sirve $)^{17}$

El perfil de interés, como explica la propia nomenclatura, identifica el interés presente en el núcleo de la existencia de una determinada situación jurídica, que puede ser patrimonial, existencial o combinar características de ambos (PERLINGIERI, 2007, p. 106). Por lo tanto, existe la coexistencia de situaciones subjetivas patrimoniales, existenciales, no patrimoniales y duplicativas (MEIRELES, 2009, p. 34) , que se caracterizan en virtud del núcleo de interés en el que se basan.

El perfil funcional de la situación jurídica analiza su propósito en vista de las relaciones socio-jurídicas $y$, dependiendo de la relevancia de la situación subjetiva, se concluye si tiene una función social o si es una función social (PERLINGIERI, 2007, p. 107). Por lo tanto, es posible clasificar las situaciones en existenciales y/o patrimoniales desde su función o propósito. La función de una situación jurídica debe analizarse, en Brasil, en comparación con la Constitución de la República de 1988, que elevó a la persona humana y su dignidad al centro del sistema jurídico brasileño ${ }^{18}$ y dio prioridad a las situaciones existenciales.

Porque la dignidad de la persona humana, como fundamento constitucional, afecta el derecho privado, exigiendo la promoción y el desarrollo de los derechos de la personalidad, ya que "aunque la Constitución brasileña no es directa sobre la protección del derecho al libre desarrollo de la personalidad, protege indirectamente salvaguardando la dignidad humana". (TEIXEIRA, 2018, p. 81).

Aquí, por lo tanto, se encuentra el criterio funcional distintivo entre situaciones jurídicas existenciales y patrimoniales cuando se prevén sus efectos sobre los derechos subjetivos de la personalidad. Por exclusión, se concluye que "[...] la situación jurídica subjetiva existe si los efectos directos y esenciales afectan la personalidad de su titular" (MEIRELES, 2009, p. 39), y las otras situaciones jurídicas se heredan.

Los perfiles de interés y el perfil funcional trabajan juntos para comprender qué son los derechos existenciales (perfil de interés) y para qué sirven (perfil funcional), siempre justificando su protección y su ejercicio mediante el cumplimiento de su función, cualquiera que sea La promoción de la persona humana. Por lo tanto, al observar las situaciones indicadas en el artículo 6 del EPD, no hay dudas sobre su naturaleza existencial.

Por lo tanto, al proporcionar plena capacidad civil a las personas con discapacidad para proteger y ejercer las situaciones jurídicas allí descritas, una interpretación literal sugeriría que la autonomía existencial privada se atribuye a las personas con discapacidad, a pesar de haber sido o ser reconocidas eventualmente su incapacidad debido a impedimento permanente, de naturaleza mental o intelectual, para expresar voluntad discernida.

Esta interpretación también podría estar respaldada por la concepción jurídica de la autonomía como un poder jurídico que el Derecho atribuye, por lo tanto, sería necesario renunciar a la relación dialógica establecida entre la autonomía privada y la capacidad de hecho, al menos en un ámbito existencial, que no es razonable en términos de lo que se desarrolló en la breve exposición teórica de ambos realizada en este texto.

17 Además de los perfiles del interés y funcional, existe el efecto, la dinámica, el ejercicio y la normativa (PERLINGIERE, 2007, p. 105-107) que, aunque integran la visión unitaria de la situación jurídica, no influyen de inmediato en la distinción entre situaciones existenciales y patrimoniales.

18 Tesisavalada, entre otras, por Maria Celina Bodin de Moraes (1993, p. 76); Rose Melo Vencelau Meireles (2009, pág. 38); Gustavo Tepedino (2012, p. 160) e lara Antunes de Souza (2016, p. 205) Ana Carolina Brochado Teixeira (2018, p. 76). 
No hay suficientes elementos para considerar una base independiente para la autonomía privada que rompa con la capacidad de hecho, incluso si solo se relaciona con situaciones subjetivas existenciales, ya que la forma de autonomía privada no se modifica por el contenido cualitativamente diferente delderecho subjetivo que instrumentaliza.

Además, algunas de las situaciones expresadas en el artículo 6 del EPD revelan situaciones protegidas por el derecho fundamental de la libertad individual que, en principio, no son objeto de la autonomía privada. En este sentido, se observa que el ejercicio de los derechos sexuales y reproductivos, con acceso a información adecuada sobre reproducción y planificación familiar, así como la prohibición de la esterilización obligatoria y el derecho a la convivencia familiar y familiar y comunitaria, indican posiciones que no constituyen,por si, hechos para los cuales la capacidad real es relevante.

Son derechos y garantías fundamentales que informan el alcance de la autonomía individual (autogobierno) de todas las personas e imponen un deber general de abstención, común a los derechos de la personalidad y universalizable desde la capacidad de derecho. Además, expresan elementos de la dignidad de la persona humana ${ }^{19}$ para los cuales se requiere una protección promocional positiva del Estado, a fin de garantizar su plena protección y, en la mayor medida posible, su desarrollo. Ello porque reclaman "[...] la autonomía no solo como un punto de partida sino también como un punto de llegada" (PALACIOS, 2008, p. 136).

Esta tutela se llama positiva, "[...] porque se lleva a cabo mediante la autodeterminación del titular, a menudo con la colaboración de otros; mientras que la tutela negativa se refiere a comportamientos omisivos generales [...] "(MEIRELES, 2009, p. 57) Por lo tanto, es posible reconocer parcialmente que la redacción dada al artículo 6 del EPD se relaciona implícitamente con una noción de autonomía externa al derecho privado que es sinónimo de libertad y autodeterminación individual, conceptos más cercanos a la construcción de los derechos humanos.

Por otro lado, casarse y constituir una pareja de hecho; ejercer el derecho de custodia, tutela, y adopción, como adoptante, son actos de derecho civil incompatibles con la incapacidad real causada por el impedimento mental o intelectual de la persona con discapacidad para expresar la voluntad discernida.

El matrimonio ${ }^{20}$, dado que la idoneidad de ambos pretendientes es necesaria para manifestar su voluntad discernida de establecer un vínculo conyugal entre sí, en la forma del artículo 1.514 del Código Civil. Por lo tanto, aunque el EPDhaya incluido en el párrafo 2 del artículo 1.550 del Código Civil, la posibilidad de que las personas con discapacidad mental o intelectual, a partir de los dieciséis años, puedan casarse expresando su voluntad directamente o a través de su tutor, es necesario reconocer la incompatibilidad del dispositivo con la propia EPD, que en su artículo 85 restringe la tutela a los derechos de naturaleza negocial y patrimonial de la custodia.

Además, los derechos subjetivos existenciales que informan el núcleo de los derechos de la personalidad son incompatibles con el instituto de representación, por el cual el representante invierte en la posición legal del representado para expresar su propia voluntad en sustitución de la que representa. Es inconcebible que alguien con una discapacidad mental o intelectual, impedido de manifestar una voluntad discernida, pueda contraer matrimonio por una voluntad que no ha desarrollado y, por lo tanto, no podría ser expresada por otros, excepto por la ficción jurídica absoluta.

La pareja de hecho, a pesar de su informalidad, constituye un negocio jurídico para el cual el ánimo consciente de comenzar una familia es indispensable. Por lo tanto, en ausencia del juicio de la persona con discapacidad mental o intelectual, no habrá una pareja de hecho.

La custodia, tenencia, tutela y adopción, porque expresan relaciones jurídicas obligatorias que, dentro del alcance de los hechos jurídicos, dependen de la manifestación o declaración (en el caso de la adopción) de la voluntad de la persona con discapacidad mental o intelectual y, por lo tanto, no pueden se considerará que existe si no hay discernimiento necesario para su manifestación o declaración consciente. Por lo tanto, aunque la manifestación y la declaración de la voluntad son medios diferentes para su externalización, para componer el apoyo fáctico del acto jurídico (stricto sensu y el negocio jurídico) la externalización de la voluntad debe ser consciente.

La aptitud del tutor y adoptante para garantizar y asumir de manera discernible la asistencia material, moral y educativa necesaria para el desarrollo de las personas bajo su custodia, tutela, tenencia o en el proceso de adopción, por lo tanto, necesariamente pasa por su capacidad de manifestar o declarar su voluntad discernida.

19 Sobre el tema, se citan las contribuciones de Maria Celina Bodin de Moraes (2006, p. 118) y AntônioJunqueira de Azevedo (2002, p. 123), que defienden la existencia de un sustrato material de dignidad.

20 El matrimonio de personas con discapacidad mental o intelectual fue abordado específicamente por lara Antunes de Souza (2018) y Raphael Furtado Carminate (2019). 
Por lo tanto, si es cierto que la discapacidad, por si, no impide el ejercicio de la custodia, tenencia, tutela o adopción, es igualmente correcto afirmar que la mejor interpretación del Artículo 6 no puede concluir atribuyendo estas facultades en detrimento de la verificación de las condiciones reales para su ejercicio. Además "eldiscernimientopuedefluctuarconeltiempo y no constituyeun concepto de 'todo o nada', es necesarioconsiderarloenel contexto de ladecisión específica a ser adoptada, o a lafunción específica a ser cumplida" (BARIFFI, 2014, p. 406).

La protección y promoción de la persona con discapacidad mental o intelectual implica, cuando sea necesario, el análisis de su capacidad de expresar voluntad consciente y discernida, de modo que las medidas destinadas a ejercer su capacidad jurídica sean proporcionales y apropiadas a las circunstanciasindividuales de la persona, según lo determinado por el artículo 12.4 de la CDPD.

Así, es posible afirmar que la interpretación literal del artículo 6 del EPD causa una distorsión de la realidad objetiva de las personas con discapacidades mentales o intelectuales que, aunque eventualmente se les impide manifestar o declarar voluntad consciente y discernida, se consideran legalmente iguales a las personas sin impedimento referido a la práctica de actos jurídicos existenciales y empresariales, ejerciendo autonomía a pesar de su capacidad de hecho.

Por otro lado, una interpretación del mismo artículo que considera la unidad y coherencia del sistema jurídico del derecho privado, en particular la construcción de la Teoría de las Capacidades Civiles de acuerdo con el desarrollo del concepto de autonomía privada, es necesario concluir que la discapacidad no afecta la plena capacidad civil de las personas con discapacidad para invertir en el poder conferido por la autonomía privada, incluso, en un ámbito existencial. Sin embargo, el discernimiento ciertamente afecta esta capacidad, ya que la imposibilidad de expresar la voluntad consciente de practicar actos jurídicos existenciales y asuntos comerciales en su ausencia.

\section{Conclusión}

El desarrollo de este texto se inspiró en el intento de dilucidar una aparente incoherencia que justifica la revisión de la Teoría de las capacidades civiles, cuando bajo la perspectiva de la capacidad de hechoy la autonomía privada existencial de las personas con discapacidad mental o intelectual, de la CDPD y el EPD.

Al promover la igualdad jurídica de las personas con discapacidad para la práctica de actos jurídicos y negocios en un ámbito existencial, a pesar del grado de discernimiento y la capacidad de manifestar y declarar una voluntad consciente, existe una ficción jurídica de que solo la interpretación literal y no unificada del artículo 6 del EPDparece respaldar. Con este fin, la ausencia de una base independiente para la autonomía privada en un ámbito existencial que puede romper con la discapacidad real está justificada, ya que la revisión de la Teoría de las Capacidades Civiles todavía depende de la manifestación y declaración de la voluntad consciente y discernida, para la cual se requiere la capacidad de discernimiento hasta cierto punto.

Por lo tanto, la hipótesis que, finalmente, se confirmó en su totalidad se deriva de la verificación de que la revisión de la Teoría de las Capacidades Civiles promueve una distorsión de la realidad objetiva de las personas con discapacidad mental o intelectual que fueron tratadas como igualmente autónomas para la práctica de actos y negocios jurídicos existenciales, a pesar del reconocimiento eventual de su impedimento para expresar voluntad discernida y consciente.

Así, el artículo 6 del EPD debe leerse de tal manera que, una vez reconocida la incapacidad de la persona con discapacidad mental o intelectual para expresar su voluntad discernida y consciente, las expresiones de libertad, los actos y los negocios jurídicos existenciales que describe debe exigir del régimen de discapacidad el apoyo y el cuidado adecuado a las circunstancias personales de la persona con discapacidad. Por lo tanto, la discapacidad afecta la capacidad civil plena, sino el impedimento mental o intelectual que impide la manifestación o declaración de voluntad discernida y consciente.

\section{Referencias}

ALMEIDA, Renata Barbosa de. (In)capacidade dos esquizofrênicos: um estudo sobre o exercício do direito à saúde. 2011. 201f. Tese (Doutorado em Direito) - Programa de Pós-Graduação em Direito, Pontifícia Universidade Católica de Minas Gerais, Belo Horizonte, 2011.

ALMEIDA, Vitor. A capacidade civil das pessoas com deficiência e os perfis da curatela. Belo Horizonte: Fórum, 2019. 
AMARAL NETO, Francisco dos Santos. A autonomia privada como princípio fundamental da ordem jurídica: perspectivas estrutural e funcional. Revista de Informação Legislativa, Brasília, v. 26, n. 102, abr./jun. 1989. Disponible en: http://www2.senado.leg.br/bdsf/item/id/181930. Acceso en: 03 dic. 2018.

BARIFFI, Francisco José. El Régimen jurídico internacional de la capacidad jurídica de las personas com discapacidad. Madrid: Grupo Editorial Cinca, 2014.

BISOL, Cláudia Alquati; PEGORINI, Nicole Naji; VALENTINI, Carla Beatris. Pensar a deficiência a partir dos modelos médico, social e pós-social. Cadernos de Pesquisa, São Luís, v. 24, n. 1, p. 87-100, jan./abr. 2017.

BRASIL. Código Civil Brasileiro: trabalhos relativos à sua elaboração. Rio de Janeiro: imprensa nacional, 1917. v. 2.

CARMINATE, Raphael Furtado. Capacidade das pessoas com deficiência mental ou intelectual para constituir família. Belo Horizonte: Editora D’Plácido, 2019.

CARVALHO, Felipe Quintella Machado de. Teixeira de Freitas e a história da teoria das capacidades no Direito Civil brasileiro. 2013. Dissertação (Mestrado em Direito) - Programa de Pós-Graduação em Direito, Universidade Federal de Minas Gerais, Belo Horizonte, 2013.

DABIN, J. El derecho subjetivo. Tradução: Francisco Javier Osset. Granada: Comares, 2006.

FERRI, Luigi. La autonomia privada. Tradução: Luis Sancho Mendizábal. Granada: Comares, 2001.

FRANÇA, Thiago Henrique. A normalidade: uma breve introdução à história social da deficiência. Revista Brasileira de História \& Ciências Sociais, Rio Grande do Sul, v. 6, n. 11, p. 105-123, jul. 2014.

FREITAS, Augusto Teixeira de. Consolidação das leis civis. Brasília: Senado Federal, 2003. v. 1.

GODINHO. Jéssica Rodrigues. O papel do discernimento na Teoria das Incapacidades. 2019. 124f. Dissertação (Mestrado em Direito) - Programa de Pós-Graduação em Direito, Pontifícia Universidade Católica de Minas Gerais, Belo Horizonte, 2019.

GOMES, Orlando. Raízes históricas e sociológicas do Código Civil brasileiro. 2. ed. São Paulo: Martins Fontes, 2006.

HUPSEL, Francisco. Autonomia privada na dimensão civil-constitucional: o negócio jurídico, a pessoa concreta e suas escolhas existenciais. Salvador: JusPodivm, 2016.

LARA, Mariana. Capacidade civil e deficiência: entre autonomia e proteção. Belo Horizonte: Editora D’Plácido, 2019.

LIMA, Taisa Maria Macena de Lima; GODINHO, Jéssica Rodrigues. O esvaziamento da teoria das incapacidades pelo estatuto da pessoa com deficiência: (re)interpretação através do discernimento. Revista da AJURIS, Porto Alegre, v. 46, n. 146, jun. 2019. Disponible en: http://ajuris.kinghost.net/OJS2/index.php/ REVAJURIS/article/view/1037/Ajuris_146\%20-\%20DT16. Acceso en: 20 jul. 2020.

LISBOA, Natália de Souza; SOUZA, lara Antunes de. Autonomia privada e colonialidade de gênero. In: CONGRESSO NACIONAL DO CONPEDI BELÉM/ PA, 28, 2019, Belém - PA. Gênero, sexualidades e direito. Florianópolis: Conpedi, 2019. p. 7-22. Disponible en: http://conpedi.danilolr.info/publicacoes/048p2018/ qxo35b07/iUwptRd3eP50905O.pdf. Acceso em: 22 jul. 2020.

MEIRELES, Rose Melo Vencelau. Autonomia privada e dignidade humana. Rio de Janeiro: Renovar, 2009. MILL, John Stuart. On Liberty. Ontario: Batoche Books Limited, 2001.

MIRANDA, Francisco Cavalcanti Pontes de. Tratado de direito privado: introdução. Pessoas físicas e jurídicas. Campinas: Bookseller, 2000. t.1. 
NAVES, Bruno Torquato de Oliveira. $O$ direito pela perspectiva da autonomia privada: relação jurídica, situações jurídicas e teoria do fato jurídico na segunda modernidade. Belo Horizonte: Arraes Editores, 2014.

NUCCl, Guilherme de Souza. Código penal comentado. Rio de Janeiro: Forense, 2017.

OLIVEIRA, Priscilla Jordanne Silva. A teoria das capacidades na emergência de um microssistema jurídico de proteção e promoção da pessoa com deficiência: fundamentos de justiça básica para integração do sistema de apoio. 2020. Dissertação (Mestrado em Direito) - Programa de Pós-Graduação em Direito, Universidade Federal de Ouro Preto, Ouro Preto, 2020.

PALACIOS, Agustina. El modelo social de discapacidad: orígenes, caracterización y plasmación en la Convención Internacional sobre los Derechos de las Personas con Discapacidad. Cermi. Madrid: Cinca, 2008.

PERLINGIERI, Pietro. Perfis do direito civil: introdução ao direito civil constitucional. Tradução: Maria Cristina de Cicco. 3. ed. Rio de Janeiro: Renovar, 2007.

PRATA, Ana. A tutela constitucional da autonomia privada. Coimbra: Almedina, 2016.

RAWLS, John. Political liberalism. New York: Columbia University Press, 1996.

ROBERTO, Giordano Bruno Soares. Introdução à história do direito privado e da codificação: uma análise do novo Código Civil. Belo Horizonte: Initia Via, 2011.

RODRIGUES JUNIOR, Otavio Luiz. Direito civil contemporâneo: estatuto epistemológico, constituição e direitos fundamentais. Rio de Janeiro: Forense Universitária, 2019.

SOUZA, lara Antunes de. Estatuto da pessoa com deficiência: curatela e saúde mental. Belo Horizonte: Editora D'Plácido, 2016.

SOUZA, lara Antunes de. Reflexões sobre os impactos do Estatuto da Pessoa com Deficiência no Direito das Famílias: curatela e casamento. In: PEREIRA, Fábio Queiroz; MORAIS, Luísa Cristina de Carvalho; LARA, Mariana Alves (org.). A teoria das incapacidades e o estatuto da pessoa com deficiência. Belo Horizonte: Editora D'Plácido, 2018. p. 203-217.

SUSTEIN, Cass R. A teoria do formalismo jurídico. In: RODRIGUEZ, José Rodrigo (org.). A justificação do formalismo jurídico: textos em debate. Tradução: Catarina Helena Cortada Barbieri. São Paulo: Saraiva, 2011. p. 201-236.

TEIXEIRA, Ana Carolina Brochado. Autonomia existencial. Revista Brasileira de Direito Civil - RBDCivil, Belo Horizonte, v. 16, p. 75-104, abr./jun. 2018.

WEINRIB, Ernest. A teoria do formalismo jurídico. In: RODRIGUEZ, José Rodrigo (org.). A justificação do formalismo jurídico: textos em debate. Tradução: Catarina Helena Cortada Barbieri. São Paulo: Saraiva, 2011. p. $259-270$.

Recebido em: 31.07 .2020

Aceito em: 23.06.2021 